\title{
COMPARISON SHOPPING IN THE PHILOSOPHY OF MIND
}

\author{
FRED ADAMS \\ Department of Philosophy, \\ Augustana College
}

These days smart shoppers are comparison shoppers. They know that, while brand name products may be advertised as special or more fancy than the competition, generic equivalents are often just as good. Check the labels and if the important ingredients are the same, there may not be as much to distinguish the brand name from the generic as the media-hype would suggest.

In recent years Fodor $^{1}$ has been conducting a media-blitz of his own in the philosophy of mind. The products advertised

1 This comes out most explicitly in the introduction to [10], although the theme is contained in other selections in the book as well. Here is what Fodor says:

Here, then, is a major theme in the essays that follow: There are two, quite different, applications of the "computer metaphor" in cognitive theory: two quite different ways of understanding what the computer metaphor is. One is the idea of Turing reducibility of intelligent processes; th ? other (and, in my view, far more important) is the idea of mental processes as formal operations on symbols [10, pp. 23-24].

I shall call these two problems that of functional properties and semantic properties, respcctively. Fodor goes on to add:

But even if functionalism is true and edify ing, it is not a solution to the problem that makes cognitive psychology special among the sciences -viz. the (apparently ineliminable) adversion to etiologies in which objects that have propositional content figure as causal agents. On this topic, functionalism is neutral, hence uninformative $[10$, pp. 24-25].

If it is not already clear from the quotations, Fodor goes on to make it clear that he does not hold these problems to have equal weight -that of the explanation of behavior in terms of functional states and that in terms of the propositional (semantic) content of mental states. He sees the latter as a far more difficult problem than the former. It is that which $I$ question in this paper. 
are two problems for theory construction in cognitive science. According to Fodor, the 'grade A-fancy' problem is semantic content-viz. how can mental states play a causal role in our psychology in virtue of their semantic content? A second problem that is getting only 'grade B' billing is the problem of functional properties-viz. how can mental states play a causal role in our psychology in virtue of their functional properties? Fodor claims that questions about functional properties (and functional explanation) are worth considering, but that they are strictly second rate compared to those surrounding semantic properties. In fact, he seems to think they have been answered-nothing turns a problem into a 'grade B' problem faster than solving it!

It is not my intention to claim that there are no qualitative differences between these two problems. For I think there are. Nor do I think Fodor is wrong to advertise the intellectual delicacy that semantic properties present to theory construction in cognitive science. I do think that if we check ingredients we will find that functional properties present a formidable generic equivalent to that of semantic content. Functional properties are as mysterious as semantic ones when accounting for their causal efficacy. That in itself will raise Fodor's 'grade B' product back to the level of 'grade A-fancy'.

Let me begin with a crucral desideratum in cognitive science, if it is truly to be a science. A theory of the mind (and corresponding science of psychology) must explain the causal efficacy of the mental. Our folk-psychological employment of mental ascriptions assigns causal roles to pains, desires, beliefs, emotions, and other mental states. Whether individually (particularism) or only in harness with other mental states (holism), they clearly seem to be causal factors in behavior and in transitions between mental states. A perspicuous science of psychology must either explain this away as an illusion (argue that folk psychology is strictly false ${ }^{2}$ ) or it must account for

2 Stich, for example, has turned the tables on us by claiming that folk-psychology is false. He, as Fodor, is impressed with the difficulty of satisfying the cons- 
the properties of mental states in virtue of which they are causal. Since Fodor is a champion of the latter strategy (de fending it against the former), we expect from him a research program that tells us which properties of mental states are law-instantiating (where the laws are causal).

More importantly, we expect it to be the mental properties of mental states which are causal and law-instantiating. This is not a necessary condition of accounting for the causal efficacy of mental states. Davidson's ${ }^{3}$ anomolous monism preserves the causal efficacy of mental states, but independently of their mental properties. On his view it is the physical properties of a mental event in virtue of which the mental event plays a causal role and is causally explanatory in our psychology. Since every mental event is a physical event (token identity), there will be purely physical laws that govern mental events. By appeal to purely physical laws we are able to account for the causal efficacy of the mental. However, Davidson freely admits, as a consequence of his view, that a science of psychology is hopeless. There are no psycho-physical laws nor pure psychological laws -causal laws which mental events instantiate solely in virtue of their mental properties (or mental descriptions, in Davidson's terminology). Mental kinds turn out not to be natural kinds. If true, they lack causal efficacy. We may still find interesting empirical generalizations about mental events which can be couched in mental descriptions, but these generalization will not express causal laws. Or, at least, they will not if Davidson is right that mental terms do not carve out natural kinds -not physical natural kinds nor any other natural kinds.

If anomolous monism saves the causal efficacy of mental

traints that our common sense attitudes place on mental states. Beliefs, say, must both have propositional content (to be true or false) and cause our behavior in virtue of the content they have. However, we also hold that beliefs must have their causal roles exhausted by the formal, purely non-semantic properties of neural states which instantiate them. Stich argues impressively that these constraints cannot be simultaneously satisfied, as they must if folk-psychological theory of beliefs is true. He concludes that folk-psychology is false. See his [13].

3 The locus classicus is "Mental Events", hut the ideas are sprinkled through Davidson's papers on the philosophy of mind and action in [6]. 
events, it does not save it in the right way. 4 For it makes the purely mental properties of mental events epiphenomenal and strictly eliminable in any causal explanation of behavior or of psychological state transitions. Davidson's view is subject to this complaint: that he has not explained the causal efficacy of the mental, as a result. Yet, even without fighting that battle, we know that Fodor does not want to take Davidson's way out of the causal efficacy problem. For Fodor wants to save psychology as an autonomous (non-reducible) special science -not junk it. He is firmly committed to the existence of psychological laws. For him, mental states must have causal efficacy in virtue of their mental properties -expressed via

4 Honderich argues this in [12]. It is in the context of presenting a theory of his own; a theory which I do not happen to accept. But independently of acceptance of his view, I think his objection to Davidson stands. In summary, his point is that Davidson's theory of intentional action requires that a mental state, an intention, cause bodily behavior for that behavior to be performed intentionally. Furthermore, it is not enough that it cause the behavior, but it must do so in virtue of its being an intention. Otherwise the connection between the intention and the action could be accidental and not yield intentional action after all. Davidson is wary of deviant causal chains outside the head, so he is not impervious to such difficulties. Honderich's point is that if it is accidental to an event's being a cause of behavior that it is an intention (it's not the mental property that is causally efficacious), that is as bad as a deviant path. This could be solved if it was the property of being an intention that was causally efficacious, not a property that the event carries only incidentally or accidentally relative to its causing bodily movement. But Davidson's anomolous monism precludes this, since intentions qua intentions cause nothing (nor do events cause anything in virtue of their mental properties or descriptions, in general), if anomolous monism is true.

Quite independently, I have argued elsewhere -on the same grounds- that Davidson's solution to the "logical connection argument" fails. Since I think that his attempt to avoid that objection, more than anything else, led to his ac. ceptance of anomolous monism, I concur with Honderich's criticism. See [1] where I trace this difficulty for Davidson through to problems of how representations can be causes in virtue of their representing properties. The problem is an exact replica of that which Fodor is dealing with in regard to semantic properties. However, I think Davidson sees, what Fodor does not, that the same type of problem crops up for functional properties as well.

In another context, Cummins hits the same nail on the head. He argues that when one tries to explain certain capacities (functional or cognitive) by droping down to the properties of the instantiations in a physical system and adverting to the subsumptive strategy of D-N explanation one actually changes the subject. One does not explain the original capacity at all. See his [5]. His criticism holds equally for functional properties and semantic properties. Note especially p. 62 for the latter and chapters 1 and 2 for the former. 
laws that quantify over mental kinds. So the causal efficacy of mental events cannot be preserved solely in virtue of the physical properties and laws that govern their instantiations. For that would land us back on Davidson's menu of culinary delights by which we cook up mental "laws" by doing philosophy not by doing serious science. Lord knows why mental events supervene on their physical bases in the way that they do if Davidson is right, but if he is right there is no chance for psychology to be the science of the mental that Fodor longs for. Nor would Fodor want to take Dennett's way out -making intentionalistic psychology an instrumental calculus of rational prediction of one another's behavior (a matter of taking the "intentional stance"). Therefore, we need from Fodor an account of the mental which preserves the causal efficacy of mental states and does so in virtue of their mental properties. This desideratum must not be far from our attention as we survey the twin-billing that Fodor gives the two problems central to our concern here: the causal efficacy of functional properties and of semantic properties of mental states (or events). For without it we have nothing to distinguish (nor save) Fodor's view from Davidson's (or Dennett's). ${ }^{5}$

5 I can imagine someone objecting at this point that $I$ am being unfair to Fodor. For I am making it sound as though he thinks mental (i.e. functional) properties are natural kind properties that have causal efficacy when instantiated. After all, he does sometimes talk as though it is only the physical instantiations that do the causal work in our psychologies. But if this is right, then I do not think there can be the sharp difference between Fodor and Davidson that we all think we see. Fodor thinks there are genuine laws in psychology, Davidson does not. Fodor think mental states carve out natural kinds, they ane just functional kinds, not physical kinds. Davidson does not. The fact is, Fodor must hold the view that $I$ am describing in order to defend psychology as a serious science - as he indeed has. See his [10]. Fodor must think that mental (functional) properties, when instantiated, do have causal efficacy or else psychological laws are not causal laws and may be strictly eliminable -as Davidson seems to hold. Davidson seems to view mental kinds (say, pains) as akin to artificial kinds (say, cups). Both are capable of multiple physical instantiation. Both are functionally specifiable. But that is where the similarity, between pains and cups must stop for Fodor (not for Davidson). For while being a pain -or any type of mental property - is held to have causal efficacy (when instantiated), being a cup is not. The short way of making this point is that being a pain is to be a natural kind property, while being a cup is an artificial kind. Being a pain is supposed to be a law-instantiating kind, being a cup is not. Pains, qua pains, cause things. Cups, qua cups, do not $\rightarrow$ or so Fodor needs to say. 
The history of functionalism, as a thesis which offers an implausibility argument against a reductionist type-type identification of mental properties with physical properties, is well known. And when it comes to recounting that history, no one does it better than Fodor. I pick up the story only where functional properties come on the scene: just after the part about how mental kinds are not physical natural kinds. For this is where we are introduced to the problem that functional properties present to psychological theory.

After the discovery that mental properties are not (cannot be reduced to) physical properties, we then have a serious decision to make. Perhaps mental kinds do not carve out natural kinds. Functional properties generally seem to be like this. After all, functional kinds such as cups and saucers, mousetraps and fuel injectors are not physical natural kinds. Not even functionalists ever thought seriously about having a science of such kinds. These are artificial kinds, if any are. The truths about them are as much decisions as discoveries. If anyone thought he had found laws which comprised a science of such kinds, he would be mistaken. Mousetrapology, what ever it might be, could not be science. So what reason is there to view mental properties (functional properties) as serious candidates to feature in laws of a special science (in Fodor's sense)? We could lump beliefs and desires with fuel injectors and mousetraps -artifacts of man's own making. If we make this choice, then the "science" of psychology is about something that we cook up, not about something we discover in nature. It leads us back to anomolous monism or intentional systems theory, not to a serious science.

One can of course change the rules of the game at this point: go instrumentalist (Dennett), re-define what functional explanation really is (Cummins), do something besides psychology -such as brain science (Churchlands). However, this is not what Fodor is advertising -a science of psychology with functional and semantic properties featured in psycho logical laws.

Fodor is a realist about mental states and mental properties -so instrumentalism about the mental is unattractive. He is 
not interested in changing fields nor trying to put the psychologists out of work. So he wants to find something for psychological laws to be about. And, most importantly, he thinks there are definite signs that the science of psychology is already in the business of discovering empirical generalizations that are law-like. But how to argue that the putative generalizations express genuine laws?

Fodor identifies mental kinds (properties) with functional kinds (properties). This spares psychology the embarrassment of wild variation of physical instantiations of a mental state type $M$ (let $M=$ your favorite mental state). What property do all mental states of type $M$ share? They share the functional property that is identical with $M$. And how do we know what property that is? Easy: functional properties are individuated via their causal roles (input/output relations). So find the causal role that mental states of type $M$ play in a person's psychology; identify the input states to $M$ and the state transitions from $M$ to other mental states or to bchavior as output: and you have it. Let alpha stand for the inputs to state $M$ and beta stand for the outputs. Then the functional property identical with mental property $M$ is the property of taking alpha inputs into beta outputs. Any physical states that instantiate the mental state $M$ will share that functional property whether they share physical properties (carve out a physical kind) or not. Therefore, there is no embarrassment to psychology. When looking for a psychological law, look for a law which quantifies over functional properties, not physical ones per se. 6

Critics of this top-down approach think it sounds a little more like a recipe than they had hoped. Before we even begin looking at the instantiations of available psychologies we seem to be assured, perhaps falsely (Block), ${ }^{7}$ that we will

6 This is just the standard theory of functionalism that is shared on one version or another by followers of Putnam, Lewis, Fodor et al. See Block's [3] for a collection of the standard literature.

7 Block [3] has been the staunchest critic to argue in this vein. He thinks it is highly unlikely that one will find the required input/output invariances that are needed to specify functional roles across all possible physical instantiations. Even 
find the input-output invariances we need for identification of functional properties (functional roles). We even seem to be assured, perhaps falsely (Churchlands), 8 that we have the right functional taxonomies prior to mucking about in the various physical instantiations themselves.

But, after we identify mental properties with functional ones, how do we know we are in the science business - not merely in the philosophy business (Davidson), 9 at best? That is, how do we know we have genuine laws? Fodor answers by elevating functional properties to the status of natural kind properties, themselves. If what it takes to have a genuine science is genuine laws, and what it takes to have genuine laws is to quantify over natural kinds; then natural kinds it will be (functional kinds are natural kinds, or so Fodor claims).10

At this point that those of us who want to see psychology

Lew is has realized there may be a difficulty and tries to handle it in a very nonstandard way. See his "Mad-Pain Martian-Pain" in [3]. Fodor is inclincd to jump to the level of abstraction of talking about information inputs and outputs. To refer to the information that a state handles as input or output ignores the physical properties of the instantiation. However, it is not clear that this is not just the problem of semantic content - the 'grade A-fancy' problem in disguise. For if it is information that is flowing through a system, then we need an account of how information can have causal efficacy - that is how an input can have causal efficacy in virtue of its having a propositional content. That takes us into the problem of semantic properties, so I will not pursue it here -for it crops up later. I do want to stress that if we jump to the level of information to specify inputs and outputs that define functional properties, then Fodor will have a hard time claiming there is asymmetry in the problems of dealing with these two kinds of properties. For the problems of semantic properties will be introduced into the very problem of the individuation of functional properties themselves. (This point is continued below.)

8 The Churchlands are convinced that functional psychology taxonomizes over kinds that are derived from folk-psychology. And if it is not utterly wrong, they arc convinced it is utterly unlikely that it is complete. A futuristic psychology that pays close attention to what we learn from the neurosciences is likely to taxonomize quite differently. But we will not discover that with the top-down approach. Time to go bottom-up! See [4].

9 Davidson goes so far as to argue that psychology is better conceived of as philosophy than as a strict science. See his "Psychology as Philosophy" in [6].

10 Fodor makes this claim virtually everywhere. See [8], [9], and [10] for a brief survey. It is part of his "only game in town"-argument. Quantifying over functional kinds (functional taxonomies) is the only way to get the useful empirical generalizations that psychology needs. Interestingly, he makes the same case for adverting to propositional attitudes (semantic content on some interpretation). 
as a serious science, along with Fodor, long for reason to put our Davidsonian doubts to rest. The challenge of anomolous monism reminds us that there may be no purely mental laws (which are also causal). If mental states are functional states, the challenge can be transformed into the worry that there may be no purely functional laws (laws ranging over functional properties alone) that are causal. What has Fodor in his arsenal to slay these doubts? What justifies us in believing that we have genuine laws in the form of psychological lawlike generalizations? Or, to put the matter in the terminology of the last paragraph, what makes us think the functional kinds of psychology are natural kinds?

It is usually about here that Fodor goes transcendental on us. Given non-reduction of functional kinds to physical kinds, if we are to have a genuine psychology its taxonomy must be of functional kinds. And what else can justify one taxonomy over another but success? He simply points out that the best justification we can have that functional kinds comprise natural kinds is to discover empirical law-like generalizations which hold in virtue of functional properties. If adverting to them gives us power and generality in accounting for the etiology of behavior, that is the best we can hope for as a justification.11

Fair enough. What more could one ask to show that a psychology based on functional kinds is genuine but to actual-

11 What Fodor clcarly needs are some impressive empirical generalizations that are law-like (counter-factual supporting). He also needs for thcse generalizations to be impressive enough that they are the stuff of which a science is made. He acknowledges that critics of both functionalism (say, Davidson) and of propositional attitude psychology (say, Stich) deny that there are such generalizations. But if there were such generalizations, then Fodor is prepared to claim that only by adverting to functional properties and semantic properties, respectively, can these generalizations be made. This argument occurs both when Fodor is defending functional properties [10] and when he is defending semantic properties [8] as properties necessary for the formulation of psyehological laws. (Another case of symmetry not asymmetry.)

My objection is that even if this is true, unless Fodor gives us some reason to think we need to quantify over functional or semantic properties to give causal explanations, he has nothing to distinguish his view from Davidson's. Also, if not, there is no asymmetry in the problems for functional properties and semantic properties. 
ly do some? Nothing quiets like success. After all, isn't psychology full of interesting empirical generalizations (counterfactual-supporting generalizations) pitched at the right level of abstraction to be about functional kinds? There are serial position effects that are systematized in learning theory; accomodation theories in psychology of perception; levels of processing differences in theories of memory. These studies and more are plausibly couched in functional taxonomies of mental states and procesess. Unless we had some special reason for thinking the empirical generalizations that are systematized in these areas of psychology do not express causal laws, it would be unfair to ask more of a functionalistic interpretation of psychological laws. 12

The problem, as Fodor well knows, is that we do have special reason to think that functional etiologies are not causal (as such). One of the curious ironies about functional properties is that, although they are individuated by their causal roles, the event of instantiating a functional property can hardly yield causal efficacy by itself. To see this let us abstractly define a functional property $F$ in virtue of its causal role in a system S. Let us say that being an F-er in S amounts to taking an electrical impulse as input and closing a switch as output. Now when we ask for a causal account of why the switch closed, it will no do to say the F-er caused it. Or better, it will not do to say that it is in virtue of being an F-er (instantiating the property of being an F-er) that the switch

12 In several places Fodor offers us such limp candidates for the empirical generalizations he needs for his transcendental argument as: "If you want that $P$ and you believe that not $P$ unless $Q$, then ceteris paribus you try to bring it about that $Q$ "; or "the usual reason for someone saying that $P$ is that he believes that P"; etc. Thesc, he says, require that we quantify over the contents of one's propositional attitudes. (Similar examples can be found for the argument for quantifying over functional properties in the sources cited above.)

$\mathrm{Now}$ I am prepared to conceed even fancier generalizations than this. For example, see my [2] where I do some functionally characterized work on memory. The problem is not merely that these gcneralizations cxist, but also what their status is. Are they causally explanatory, or just place-holders for causal explanations that are not couched in the functional or semantic idiom at all? If the latter, then they are strictly eliminable for anything but heuristic or instrumental purposes. See Dennett [7]. 
was closed, because of a constraint that became popular surrounding the old "logical connection argument".13 The descriptions "being an F-er" in $S$ and "being the cause of the switch closings" in $\mathrm{S}$ are logically connected. We could find another description of the F-er (in terms of its physical properties) that would be logically independent of its effect. But then we would not have causally explained the switch closings in terms of their being caused by an "F-er." Replacing talk of descriptions with talk of properties, the point is that the property of being an F-er is not causally explanatory qua being an F-er. It is only in virtue of the purely physical properties of its instantiation in $S$ that we get a genuine causal explanation of the switch closings in $\mathrm{S}$. We would have a causal explanation in terms of a causal law, but the functional property of being an F-er would be strictly eliminable. This, however, is what must not be true if functional properties are causally efficacious ( $q u a$ functional properties, as they say). Needless to say, we are back in the Davidsonian soup -functional etiologies will be causally anomolous! What has become of Fodor's transcendental advertising campaign for the causal efficacy of mental (=functional) properties? F-ers are switchclosers, but being a switch-closer is hardly what causes the switch closing (or at least not qua being a switch-closer).

What is Fodor's response to this? He is not unaware of the problem. In fact, he thinks it has been solved! Unfortunately, however, his solution begs the question. He recognized this problem under the rubric of "the Molière-problem". 14 His answer to the Molière-problem is that we know functional etiologies are causal because we know we can build Turing machines that realize them. But, of course, this misses the point entirely. We know that we can build F-ers and mouse-

13 Davidson [6] used this argument (and its solution) in devcloping anomolous monism. You break the logical connection by describing a mental state in terms of its physical properties alone. You could do the same for the descriptions of states which instantiate functional properties. But to do so is to change the subject to the extent that your explanation is no longer about functional properties or functionally described instantiations. See note 4 for references.

14 See [10], pp. $12 \mathrm{ff}$. 
traps and doorstops too. We know that the structures which instantiate these functional kinds are causally efficacious. What we do not know is that the functional properties of these devices are natural kinds. Nor do we know that instantiating a functional property is itself causally efficacious. And unless Fodor gives us some reason to think the latter is the case, he has not solved the Molière-problem after all. The problem of the causal efficacy of functional kinds (functional properties) remains. Fodor has yet to show that a functionalistic psychology is more than (to borrow from Cummins) a mere play-by-play commentary rather than a genuine etiology. 15 He has failed to distinguish his view from Davidson's or Dennett's-much less improve upon theirs.

The separation of functional properties from semantic properties is our next concern. Fodor ${ }^{16}$ is considerably exercised to keep them apart. He points out that functional analysis of a system is neutral on matters concerning content and so it is. Any system can have its capacities functionally analyzed -a door stop, a fuel injector, a mousetrap or a digital computer. Only when the functional analysis requires that some of the system's proper functioning performs operations on symbols -items with a representational content- do we become embroiled in matters of propositional attitudes or semantic

15 Cummins has argued that if we just abandon what he calls the "subsumption strategy" of explanation and move to what he calls "functional analysis" the objection I am running folds. For then we do not need for functional properties or semantic properties to be natural kinds. Nor do we need to give explanations in which a mental state's instantiating these properties has causal efficacy. But notice, Cummins' strategy is no different than Davidson's anomolous monism and Fodor does not want that.

Cummins may object that his view is different than Davidson's because he thinks you do get genuine causal explanations on something other than the subsumption strategy. I suppose Fodor could go this way. But if he docs, then he could not hold the asymmetry for functional properties and semantic ones. On Cummins' proposal a mental state's instantiating either type of property could have causal efficacy. If Fodor took his way out of my objections, then both problems would be solved -both types of properties have causal efficacy and can be used in causal explanations in psychology. So Fodor would still not have the asymmetry that he is advertising. See Cummins [5].

16 This is part of the general asymmetry that we have been challenging. See [10], pp. 11-31. 
content. So doorstops don't and fuel injectors don't and mousetraps don't, but brains do and perhaps computers do so embroil us.

Fodor is surely right that functionalism has been silent on matters of content for too long. But it is not clear that it should be for anything more interesting than mousetraps and their ilk. In fact, if mental states are the target, it is not clear that the issue of functional analysis and semantic analysis can be cleaved in the way he proposes. We can agree that mental states are functional states. But which functions are the mental ones?17 Functionalism has been silent on this issue. The mark of the mental is a museum piece that is only recently being dusted off by functionalists. Fodor seems to think that the mental functions are the cognitive ones, primarily. Noncognitive states, emotions or sensations, get included by courtesy, since they are hooked up to cognitive systems. If this is Fodor's view, then the core mental functions are the ones that take information as input, perform a computation with that information, and give information as output. If correct, functionalism cannot be silent on the matter of representational content, for that is what is required for information to flow. Information, after all, is carried by items (tokens) with representational content in some form. Which functions are the mental ones? The ones that handle information in some unique way. Of course, we must say what distinguishes mental processing of information from other kinds, but the surprising part.is that Fodor thinks we could do an analysis of mental states and still be silent on how functional properties and semantic properties become intertwined? However, it's unlikely that we can. Cognitive functions (=the mental ones, par excellence) must not be analyzed independently of

17 Functionalists have been silent on the mark of the mental for too long. Saying, as Fodor does, that inental states (cognitive ones, anyhow) are information processing states is unhelpful. Which are the mental ones? I have heard Fodor deliver a paper on the topic "Why Paramecia don't have mental states". But this is a recent fling. Apparently, he too thinks this is a project for functionalism who's time has come. I think the topic is also receiving ncw attention under the heading of minds and machines - which is back "in" again. 
the fact that they process symbols with informational values (semantic properties). Therefore, the functions which are mental must be analyzed as information processing functions.

Fodor conceeds the last point, so the disagreement is whether the semantic (informational) values are essential ingredients or accidental to the functional analysis of the mental states. I am suggesting that the directions for cooking up a mental system (as functionally specified) will not leave the semantic properties to be added as if frosting, but will be listed right on the package of functionally specified ingredients for baking a mental cake.18

If Fodor's reason for keeping functional analysis and semantic analysis of mental states distinct is that we can talk about the functional roles of belief and desire without specifing propositional content for specific beliefs or desires, then there is no disagreement. But if he holds that we can give the functional roles without mentioning that the inputs and outputs of mental functions are items with semantic content, that flies in the face of his entire program for cognitive psychology. 19

18 See [10], pp. 20 ff.

19 A functional analysis of inental states which says that cognitive functions are essentially information processing functions must analyze the inputs and outputs at the level of information (not, say, at the level of physics or neurophysiology). But then cognitive functions will be defined in terms of inputs and outputs which have semantic (propositional or infornational) content.

If, as Fodor sometimes says, the symbols have semantic content, but the functions defined on them arc only computationally defined, then semantic properties could not be necessary to explain the psychological generalizations at hand. Fodor seems to want to have it both ways: semantic propertics are necessary to save the generalizations of psychology, but they may not play any causal or explanatory roles. (This holds for Fodor's "narrow content" - not just truth-functional content or "wide content".) I have avoided going into the distinction between the thrce possible ways to individuate propositional attitudes: in terms of their truth-functional content, in terms of their syntactic (formal or non-truth functional) content, and in terns of their transducer content. To do so would add needless complication for the very same problems arise no matter how mental states are individuated. Fodor concecds that individuation of mental states via syntactic features reduces to the problem of functional roles and functional properties pure and simple. And the problem of individuation in the other two ways is just the problem of semantic properties - under a maximally wide or less wide interpretation. See especially [8]. 
That brings us to the end of the 'grade B' problem, in Fodor's eyes. I have tried to elevate it to the level of 'grade A-fancy', since Fodor has not shown that functionalism fares better than Davidson's anomolous monism or Dennett's intentional stance for psychological laws. Functional properties, despite Fodor's advertisement, are impotent candidates for properties to feature in causal laws. They do not give us what we need -natural kinds for psychological laws to be about. Let us now turn to semantic properties -Fodor's 'grade A-fancy' problem for psychology. I will suggest that there. cannot be the asymmetry of problems Fodor is claiming.

To begin, a semantic property - like a functional propertyis capable of being multiply instantiated in an indefinite variety of physical ways. A picture of Aunt Sally can be made out of nearly anything. What makes the picture "of Aunt Sally" has little to do with its physical properties alone. Its etiology is crucial in ways that what it is made of is not.

Fodor thinks of belief as a relation between a subject and a syntactic item with representational content -a symbol. A belief about Aunt Sally has both the functional part -the functionally specified "believing relation"- and the bit that is "about Aunt Sally" - the symbol with representational content. The point I stress is that both the functional part and the symbol part are equally subject to multiple physical instantiation. Fodor is well aware of this and treats propositional attitudes accordingly - when he argues for the autonomy of psychology it is sometimes with reference to the non-reducibility of the functional bit and sometimes with reference to the non-reducibility of the symbolic (semantic) bit. That is, he wants to say laws of psychology are essentially about mental states individuated both as functional kinds and as kinds with semantic content. Neither of these can be eliminated in favor of generalizations which advert solely to the physical properties of the instantiations. This preserves the autonomy of psychology's laws. ${ }^{20}$

But if functional properties and semantic properties share

20 See Fodor's [10] chapt. 9 and the introduction as well as [8]. 
non-reducibility, then at least in this regard we should expect the same set of difficulties with each. Exact worries about the non-naturalness of functional and semantic kinds transfer. The suspicion of the anomolousness of the mental in both aspects should hold. Therefore, rather than expect a special difficulty for one aspect of the mental and not the other, we should expect it to be difficult for either to be causally efficacious. For Davidson-like worries will attach to both functional properties and semantic properties as law-instantiating.

Why does Fodor think otherwise? For one, as noted, he thinks he has a solution to the question of how functional properties can be causally efficacious. And if he were right, that would indeed suggest that semantic properties present a different quality or level of difficulty -assuming there were no corresponding solution for semantic properties. But his solution is hardly satisfactory. Merely pointing out that we can have Turing machines which instantiate systems functionally described does not show that the functional properties of the system are doing any causal work. Indeed, if it were that easy to show a type of property has causal efficacy, then we might announce that we have solved the 'grade Afancy' problem of semantic properties as well. For, after all, we have Turing machines that instantiate psychological descriptions which hold in virtue of semantic content too. Namely, us! Either Fodor's solution should work for both types of property or for neither. Since he does not think it works for semantic properties - lest there would be no special problem about them - it should not work for functional properties. either.21

Another reason is that he comes at the problem of semantic properties in a slightly different way. There are at least three ways to arrive. One is the way we got here -the Davidson expressway. This is the most direct route. If semantic proper-

21 Fodor could take Cummins' solution, which would be consistent with his solution to the problem for both functional properties and semantic properties. But to do so would be to join forces with Davidson, and Fodor is commited to an omolous monism's being false. See note 15 . 
ties do not reduce to physical properties they are not causally efficacious. (No asymmetry of problems here!)

Then there is the Block route. ${ }^{22}$ We can come at semantic properties as does Block when he attacks functional properties in general. We realize that there need be nothing physically the same -in any interesting sense- about two believers of the proposition that Aunt Sally is a Democrat. So how do phy. sically dissimilar believers believe the same thing? How do their similar beliefs lead to the same actions, if they are phy. sically dissimilar? How can they instantiate the same functional psychologies, if they are so physically dissimilar in interesting (non-trivial) ways? How can there be a functional psychology which gives us genuine causal laws and ignores major physical differences? In some ways this is the semantic parallel of what we'll call "Block's problem" - the challenge of finding a level of description which individuates functional kinds in the right way to answer these questions. As we recall, his answer is that there is no such level of description. He too thinks Fodor has not solved the functional property problem. He just puts that complaint in a different way -the challenge of "the inputs and the outputs". As I see it, this is a search for a way to make functional kinds natural kinds by finding something invariant among inputs and outputs across systems. If we can rise to a higher level of abstraction in describing the inputs and outputs -such that they comprise natural kindsthen the property of mediating the inputs and outputs may be a natural kind property as well. Our critiques join forces, for the problem of the inputs and the outputs generalizes to both functional properties and semantic properties. If the inputs and the outputs are different -as they must be in relevantly dissimilar physical systems - then we will have to find a level of description in which they are still the same, if systems share the same semantic contents. For suppose two systems are so physically dissimilar that they cannot take the same class of inputs and outputs. Let us say their physical

\footnotetext{
22 See [3]. Block does not carry nis argument over into the context of semantic properties. He docs, however, recognize the problem and I think it is available to him to make the transition.
} 
transducers are non-equivalent. Then it is far from clear that they could process the same inputs and outputs. And, if not, it is unlikely that they can have mental states with the same semantic contents. (The natural move is to transcend to the level of information -that is what remains invariant across inputs and outputs. But information is hardly a natural kind that can yield a causal relation in virtue of a structure's instantiating it. So this move does not - without much more elaboration- solve the problem we are addressing.) Thus, even the task of explaining how physically different systems can instantiate beliefs with the same semantic content faces Block's challenge of the "inputs and the outputs". If we err on the physical side (don't abstract enough) we land in chauvinism -only systems transducer equivalent to us share semantic contents of our mental states and our psychology. If we err on the side of abstraction (stray too far from the sorts of inputs and outputs physical systems like us process) then even systems that do not share our psychologies are classified as thinkers -chinese rooms, homunculi-headed artifacts, current computers. But whichever way we go, chauvinist or bleeding-heart liberal, we must solve Block's problem by finding a level of description which carves out kinds that are capable of supporting causal laws. It is far from clear that this has been done. (No asymmetry of problems here? $)^{23}$

The way Fodor gets here is a bit different: by realizing that even if two believers are physically identical, they may believe different things. What one believes is a function not only of what is in his head, a symbol or concept, but of what that symbol means - what it represents. This extends outside of the head to its referent. Although two believers share phy-

\footnotetext{
23 Fodor's move to search for "rarrow content" - something which can causally explain behavior and still resists reduction to physical properties or computational ones derives from this pressurc. However, I have been steadfastly maintaining that his solution will not work for scmantic properties (content) cither "narrow" or "wide". It will not work for precisely the reasons that his solution to the functional properties problem does not work -hence, my objection to the asyminctry of problems.
} 
sically identical tokens of a type of symbol, those two tokens may represent entirely different things in the world. Physical identity of tokens does not guarantee identity of reference -identity of content or symbol-type (semantic identity). Two pictures of identical twins may share the same properties of chemical elements on film. Still they are pictures of two different individuals. As Putnam has taught us, meanings "ain't in the head" any more than pictures are solely in the film. Meaning relations are as non-reducibly relational as picturing relations. Trick two unsuspecting folks by controlling their environments life long, and we bring them to have beliefs with different contents, though what is in their heads may be as physically similar as you please. ${ }^{24}$

Tell a Twin-Earthish story about two believers T'om and Twin-Tom. Keep them separated (as if on different planets). In Tom's normal environment, he is acquainted with his Aunt Sally, who is a Democrat, and Tom comes to believe "Aunt Sally is a Democrat". Twin-Tom, the victim of a life long hoax, is physically secluded from Aunt Sally, who is on a different planet with Tom. There is someone who is introduced to Twin-Tom as "Aunt Sally" viz. Uncle Milton who is in drag and so similar to aunt Sally that Twin-Tom could not distinguish them. Twin-Tom comes to believe "Aunt Sally is a Democrat". Each Tom may be as physically identical as you please, but since life long their beliefs are formed on different persons - Aunt Sally or Uncle Milton (but not both)their beliefs have different referents. Tom's Aunt-Sally beliefs are about Aunt Sally, but Twin-Tom's Aunt-Sally beliefs are about Uncle Milton. The physically indistinguishable tokens

24 Fodor's recognition of the problem of semantic propertics derives from this problem. See [8] and [10] chapter 9. Despite difficulty, he thinks we still nced to appeal to content (narrow if not wide content) to do psychology. Others impressed with the same problem arc willing to ban content (narrow or wide) for psychology forever. See Stich [13] for the contrary argunent. I think Stich holds, as I do, that if semantic content is not playing a causal role, Fodor's arguments to save it are irrelevant to cognitive science. If it does play a causal role when instantiated, then Fodor has not told us how. (Remember, that is the exact structure of iny argument against functional properties -substitute "functional" for "semantic" properties.) 
of symbols in their heads are symbols with different meanings, since they have different referents. Their beliefs would even have different truth values should they both meet the real Aunt Sally while the hoax is still undiscovered. Tom's belief that this is Aunt Sally would be true and Twin-Tom's belief false.25

We shall assume that the causal story about the behavior of Tom and Twin-Tom - when they have their "Aunt-Sally"-type beliefs (as they would describe them)- supervenes on the physical properties of what is in each of their heads. Their causal stories must be the same, since they are in physically identical states. The contents of their beliefs vary. So how could content (semantic properties) play a causal role in the explanation of behavior for our "Aunt-Sally believers?" It seems that it could not and that content must drop out. Thus, we have a different avenue of approach to the same place, viz. that psychological generalizations which advert to content (widely individuated) could not express causal laws. But this is just where we had gotten with the problem of functional properties. (No asymmetry here!)

The last place for a wedge to be driven between functional properties and semantic properties is supervenience. If functional properties supervene on physical properties but semantic properties do not, then we get room for the asymmetry Fodor is advertising. Or, at least, that is a strategy available to Fodor. In the long run I doubt that it will work. For even if functional properties do supervene on physical properties, the problem we have raised about their causal efficacy will not go away. Recall that Davidson's anomolous monism was built on the premise that mental properties supervene on the physical. But that was not enough to overcome their anomolousness when it comes to causal laws. So unless Fodor has an answer to Davidsonian worries - and I have shown that he has none- supervenience alone cannot be the difference twixt the grade $B$ product and the grade A-fancy.

Even functional properties only supervene on physical pro-

25 See Stich [13] 
perties if the right background conditions are held fixed. I have an old railroad spike that I keep on my desk for a paperweight. Its physical properties are no different now than when it was holding rails not far from where I grew up. But its former function is not being fulfilled. Surely its ability to function as a paperweight supervenes on its physical properties as of now. But which functions supervene, and when, is not simply a matter of the physical properties it has. The slogan "no functional difference without a physical difference" is not strictly true of the spike. It is physically no different now, as a paperweight, than it was before, as an anchor in a railroad tie. So the supevenience relation holds only in the proper network -only where a whole set of inputs and outputs is held constant in the entire network.

The same is true for mental functions. The functional properties a neural state has may supervene on the physical properties of the neurons, but only in the right network of other states -in the right total context.26 Whole neural assemblies could, in principle, be re-wired. A functional organization of little black boxes nested in sequence could be altered by changing the sequence or lifting out a module and putting it in a different place. This would presumably change its functional role if placed in a network that is performing a different job. So the supervenience of the functional on the physical is subject to the same sort of tricks (change of context) as the supervenience of the semantic.

But once we see that the entire context has to be taken into consideration even in the case of functional properties, then we have lost the asymmetry with the case of semantic properties. For we only get failure of supervenience of semantic properties when we ignore the broader context. Remember that when we take the railroad spike out of the proper context, its functional properties do not strictly supervene either -at least not its railroad functions.

26 The very same keys on my word processor can be escape codes or delete functions or just letters of the alphabet -all depending on the other inputs and outputs that comprise the entire network. Countless otlıer examples are available. I see no reason why this does not apply to the brain as well. 
One could object that functional roles are specified counterfactually. So the spike's functional properties of being a railroad spike still supervene on its physical properties since, were it in the proper context, it would perform that functional role. But notice its paperweight functional role can be specificd counterfactually as well. Yet it is actually performing the function of being a paperweight now -not the function of being a railroad spike. I have only claimed that which functions something instantiates and when do not strictly supervene independently of context. Also notice we could say the same thing counterfactually of Twin-Tom's belief state. That is, were it formed in the environmental context of Tom's belief state, it would be the belief that Aunt Sally is a Democrat. It would be a belief about Aunt Sally, not about Uncle Milton. So semantic content only fails to supervene on physical state and functional role if we ignore broader environmental context -exclude context in specification of what counts as the "inputs and the outputs" of the belief state itself. But surely, which content a belief has (and when) must depend on the broader context, not ignore it.

In all of the Twin-Earthish examples, that is precisely what is done. The context is not held fixed. It is allowed to vary and when that happens, it should be to no one's surprise if semantic properties do not supervene on physical properties (nor even functional ones, for that matter). But if the context of inputs and outputs is broadened to an entire network (environmental context) of inputs and outputs and is held fixed, then even semantic properties supervene on physical ones. Just as for the railroad spike, if you keep it in the right network of inputs and outputs, its functional properties are strictly determined by physical properties plus context (of inputs and outputs -other spikes, local forces, joining railroad ties, etc.). And if you hold the inputs and outputs (environmental context and informational inputs, etc.) fixed, then you will indeed get supervenience of the semantic properties of mental states upon their physical (and functional properties) as well. Take two pictures of the same twin, and the picturing relation supervenes on the physical properties of the 
photographic film. Or put Tom and Twin-Tom in the same environments and hold them fixed. Then the content of their beliefs will indeed supervene on the physical properties of the symbols in their heads. For then these symbols will be nested in a broader context in which the informational inputs are held fixed.

There is not, therefore, the radical difference of supervenience for functional properties, but not for semantic properties, that one might at first expect. Whether a semantic property or a functional property is going to supervene on a physical one is dependent on the broader context of the input and output network -the broader environmental context, as it were. For that reason, even the last attempt in Fodor's route to the problem of semantic properties will not generate the asymmetry that Fodor wants for the problems of functional vs. semantic properties. The supervenience or lack of it for both sorts of propertics is not an absolute matter. It has to be relativized to broader context and when that is seen the wedge used to divide the problem is blunted.

That concludes our discussion of the problem of semantic properties. My efforts have not been directed tow ard the end of showing the difficulties of incorporating functional properties and semantic ones into psychology cannot be overcome. The only negative thesis I have been urging is that there is not the asymmetry with regard to these properties that Fodor has advertised. Indeed, my view is that these problems stand or fall together. A solution to one problem will show the solution to the other. However, Fodor has not shown us the solution to either (not yet, he may be getting close). 27

My diagnosis of each problem has been that they have the same ingredients -despite Fodor's opinion to the contrary. For the feature of each property (functional and semantic) which causes difficulty is its relational nature. A structure's having a function, as its having a content, is a relational mat-

\footnotetext{
${ }^{27}$ Fodor is moving in the direction that $I$ tend to prefer in somc of his more recent papers [8] and [11]. He Drings in the notion of teleology to account for content. I am inclined to go one step further and analyze telcological processes with control theory.
} 
ter. This accounts for the non-reduction of these properties. A reduction to a physical property would attempt to reduce an essentially relational property to an essentially nonrelational one -the property of being made of a kind of stuff, or having some specific physical properties. The history of functionalism has been the detailed account of why this will not work.

To solve the problems we have raised requires giving an account of causal relations such that a structure's instantiating a relational property (either functional or semantic) can be causal. If this can be done there is no reason in principle why both functional properties and semantic ones cannot have causal efficacy -that is, instantiating these properties can. To pull this off, both the inputs and outputs which comprise the entire functional network must be brought into the account. For, as we have seen, the entire network or context must be brought in when explaining how a structure comes to instantiate a function or have a semantic content of a certain type. In essence, we can solve the problems we have been facing only by showing how the environmental context of a system (with internal states) can play a causal role in the explanation of the system's behavior.

What might such an account look like? Short of trying to solve this problem in detail, we can speculate briefly on the answer. A system's being in a particular environmental context (entire network of inputs and outputs) will put its internal states into certain relations with the environment. The difficulty lies in explaining how instantiating those relations can have causal efficacy. For it would appear that the causal explanation of a system's behavior need not refer to anything beyond the system's skin. Whatever is going on inside seems physically sufficient to yield causal explanations of the sys. tem's behavior. This apparent sufficiency of the purely physical explanation is what causes trouble for reference to both the function that physical structures instantiate and the content. Reference to each sort of property seems strictly eliminable. (At this point Davidsonian and Dennettian intuitions run wild.) How do we get the fact that a structure instantiates 
a particular function (since nested in a functional network) or a particular content (since nested in an entire environmental context) to play a causal role in the system's behavior?

The answer seems to require that the context (or network of input and output relations - as I have been calling it) be able to alter the system's internal organization. And the only sort of system's in which we know that this can occur are control systems ${ }^{28}$-that is, systems with information control loops that can monitor their own cognitive economy and change their internal organization in response to information received from the environmental context. A system which can actually monitor the environment and make changes in its internal states (and resultant behavior) based on information it receives about the environment is required. We expect the functional economy and cognitive content to have efficacy in a teleological system. And we hope that a science such as cybernetics (control theory) will be able to provide us with the solution to the metaphysical worries which have plagued us. That is, we expect such a science to show us how relational properties can be natural kind properties -or at least how they can have causal efficacy in a system's cognitive and functional economy. If this is not far from correct, then we would expect help from control theory (in all its forms) in the solution of the problems of the causal efficacy of both functional properties and semantic properties. I am inclincd to think that we will find the solution to both problems in this area.

The thrust of this paper has been that regardless of whether one is optimistic (problems for functional properties and semantic properties will fall) or pessimistic (problems for both will stand), they stand or fall together. We have arrived at that conclusion by doing a bit of comparison of problems surrounding each. The non-reductionistic (essentially relational) nature of both types of properties is the source of the difficulty that we face. For that rcason, the essential ingredients

28 See my [1] where I show how control theory handlcs somc of the problems related to the content of internal representing structures. 
of each problem are the same despite the asymmetry of advertising.

R E F E R E N C ES

[1] Adam8, F.R., Goal-Directed Systems, Ann Arbor: Microfilms International, 1982.

[2] Adams, F.R., \& A.M. Glenberg, "Type I Rehearsal and Recognition", Joumal of Verbal Learning and Verbal Behavior, 17 (1978), 455-563.

[3] Block, N., Readings in Philosophy of Psychology, Vol. I, Cambridge: Harvard University Press, 1980.

[4] Churchland, P.M. \& P.S. Churchland, "Functionalism, Qualia, and Intentionality", Philosophical Topics, 12 (1981), 121-145.

[5] Cummins. R., The Nature of Psychological Explanation, Cambridge: MIT (Bradford), 1983.

[6] Davidson, D., Lssays on Actions and Events, Oxford: Oxford Univcrsity Press, 1980.

[7] Dennett, D., Brainstorms, Cambridge: MIT (Bradford), 1978.

[8] Fodor, J.A., "Narrow Content and Meaning Holism", Unpublished Manuscript.

[9] _ Psychological Explanation, New York: Random House, 1968.

[10] __ Representations, Cambridge: MIT (Bradford). 1981.

[11] "Semantics Wisconsin Style". Unpublished Manuscript.

[12] Honderich, T., "Psychophysical Lawlike Connections and Their Problem", Inquiry, 24 (1981), 277-303. Sce also "The Argurnent For Anomolous Monism", Analy sis, 42 (1982), 59-64.

[13] Stich, S., From Folk Psychology to Cognitive Science, Cambridge: MIT (Bradford), 1983. 


\section{RESUMEN}

El funcionalismo se ha convertido rápidamente en la concepción preponderante en la filosofía de la mente y en el nuevo campo de la ciencia cognoscitiva. El funcionalismo y, en general, la construcción de teorías en estas áreas, se enfrentan a dos obstáculos: las propiedades funcionales y las propiedades semánticas. Éstas constituyen obstáculos porque no está claro cómo puede tener eficacia causal la ejemplificación, en una estructura, de una de estas propiedades. Parecería, no obstante, que las generalizaciones psicológicas que empleamos - nuestros principales candidatos a leyes causales en psicología- cuantifican tanto sobre propiedades funcionales (propiedades mentales entendidas como propiedades funcionales) como sobre propiedades semánticas (los contenidos proposicionales de los estados mentales cognoscitivos).

En años recientes, Jerry Fodor ha llamado nuestra atención sobre ambos problemas. Al problema de la propiedad funcional lo denomina el "problema de Molière"; el problema de la propiedad semántica ha venido a ser conocido como el "problema del solipsismo metodológico". Si bien Fodor reconoce ambos problemas, no cree que los dos tengan la misma importancia. Niega que los dos se sostengan o caigan juntos y defiende que el problema semántico es, con mucho, el más difícil de los dos - puesto que el problema de la propiedad funcional ha sido finalmente resuelto, mientras que el problema semántico no lo ha sido.

En este artículo sostengo que Fodor se equivoca. Los dos problemas corren la misma suerte - ambos tienen el mismo origen y la solución de uno de ellos conduciría probablemente a la solución del otro. Afirmo también que es falso que el problema de la propiedad funcional haya sido resuelto. Señalo, por último, un sitio en el que puede buscarse una solución a ambos problemas. 